\title{
EL DESIERTO DE LOS TÁRTAROS: UN PARADIGMA DE LOCUS
} MELANCHOLIAE

\author{
BEGOÑA ALONSO MONEDERO ${ }^{1}$
}

IES Venancio Blanco

\begin{abstract}
Resumen
La fascinación que ejerce en los lectores El desierto de los tártaros de Buzzati es indisociable del espacio y de la atmósfera creados en esta novela. Este trabajo estudia los elementos que configuran ese laberinto de tiempo que es la fortaleza Bastiani, y a los "enfermos" que por él transitan, como un paradigma contemporáneo de locus melancholiae. La novela de Buzzati construye, quizá mejor que ninguna otra novela del siglo xx, un escenario simbólico difícilmente superable en la representación de la tragedia de la vida humana.
\end{abstract}

Palabras clave: laberinto, melancolía, desierto, tiempo, espacio.

\begin{abstract}
The fascination that Dino Buzzati's Il deserto dei Tartari has exerted -and still does- on its readers is closely linked to the space and atmosphere it creates. This paper deals with the elements that contribute to generate a labyrinth of time like a perfect paradigm of a locus melancholiae. Buzzati's novel stages, as no other 20th-century novel, the tragedy of modern-day human beings.
\end{abstract}

Keywords: labyrinth, melancholy, desert, time, space.

$\mathrm{E}$ s posible que las generaciones venideras no se resignen a olvidar esta novela, decía Jorge Luis Borges de El desierto de los tártaros, a la que incluyó como una obra maestra imprescindible en su biblioteca personal; y más que una valoración de la obra parece la expresión de una inevitable afinidad. No extraña que el escritor argentino se dejara cautivar por el microcosmos espacio-temporal que diseña la novela, el estrecho laberinto de conductos que se bifurcan y multiplican en torno a un héroe solitario, «regido por el método de la postergación indefinida y casi infinita»². El desierto de Buzzati, como veremos, seduce con fuerza a todo aquel que se atreve a entrar en él y no tema enfermar de tiempo y melancolía, ese laberinto “donde no hay

1 IES Venancio Blanco. Correo-e: begoalonsomon@yahoo.es. Recibido: 14-01-2010; segunda versión: 2803-2010.

2 Borges (2005). 
escaleras que subir, ni puertas que forzar, ni fatigosas galerías que recorrer, ni muros que te veden el paso" ${ }^{3}$.

Ciertamente, entre los temas de fondo propios de la narrativa de Buzzati y que, sin duda, son centrales en $\mathrm{El}$ desierto de los tártaros están el transcurrir irrefrenable del tiempo, la decadencia física, la inútil espera de los acontecimientos importantes, la conciencia de una existencia equivocada..., la vida que aspira a la gloria de la épica y, sin embargo, se colma de aliento trágico. Según Rafael Argullol (2008: 25), existe una tragicidad que se muestra, después de Shakespeare y del sentimiento trágico del Romanticismo, en su "tercer acto", en autores como Nietzsche, Kafka o Beckett. Creo que, desde este punto de vista, se puede afirmar que El desierto de los tártaros conecta con ese «hilo trágico» de que habla Argullol, alrededor del cual se configuran obras de la filosofía, de la literatura y el arte como representaciones de una determinada concepción trágica del hombre y del mundo.

Al margen de las frecuentes comparaciones de Buzzati con autores de la literatura fantástica o del absurdo, conviene destacar cómo el escritor italiano es capaz de construir en este relato, una fábula en la que, asentado en la realidad, todo el paisaje que en ella se dibuja aparece no solo como un entorno geográfico, o como un escenario físico para la acción, sino también como un espacio psicológico para los hombres que lo habitan, y todo un ámbito claustrofóbico para el ejercicio de la conciencia del ser humano, un laberinto en que perderse o desaparecer.

Cumple esta obra, por tanto, con una de las más importantes funciones de la literatura, la de crear ámbitos en que el hombre pueda ensayar, a través de la representación estética, su comprensión de conceptos como el del tiempo y el conocimiento de su propia condición. La vida de Drogo, el protagonista, realizará ese viaje al desierto y transcurrirá por el interior de la Fortaleza Bastiani, y de sus laberínticos muros, hasta el momento en que encuentra la salida, el momento en que puede, por fin, reconocerse a sí mismo. A este respecto, quizá no sea exagerado afirmar que esta novela de Buzzati configura, mejor que ninguna otra novela del siglo xx, un espacio literario paradigmático como locus melancholiae, una geografía o un escenario poéticos difícilmente superables para la representación simbólica de la tragedia del hombre contemporáneo.

\section{TRANSPOSICIÓN DE LA REALIDAD A LA FÁBULA}

El estilo de las narraciones de Buzzati -se ha dicho-delata su oficio de cronista, sus descripciones son rápidas y realistas, y en seguida sobrepasan el plano de la crónica al «piano fantastico e surrealistico» (Metallo, 1982: 616). Buzzati parte de lo real cotidiano, de lugares comunes que, sin embargo, en su obra pueden adquirir aspectos nuevos,

\footnotetext{
$3 \ll$ iOh, rey del tiempo y substancia y cifra del siglo!, en Babilonia me quisiste perder en un laberinto de bronce con muchas escaleras, puertas y muros; ahora el Poderoso ha tenido a bien que te muestre el mío, donde no hay escaleras que subir, ni puertas que forzar, ni fatigosas galerías que recorrer, ni muros que te veden el paso». Luego le desató las ligaduras y lo abandonó en mitad del desierto...» Borges (1989a: 607)
} 
obsesivos, o angustiosos. La crítica ha llamado la atención sobre esa difícil transición que se produce en sus textos entre lo que es real y lo que es imaginario. Ciertamente, ello parece ajustarse al caso de esta novela. Buzzati la escribe al finalizar su jornada en la redacción del periódico, trabajando de noche casi durante un año, hasta que termina la obra en marzo de 1939. Es su experiencia de la rutina improductiva de su trabajo en la redacción del periódico la que está en el origen de esta narración:

Probabilmente tutto è nato nella redazione del "Corriere della Sera". Dal 1933 al 1939 ci ho
lavorato tutte le notti, ed era un lavoro piuttosto pesante e monotono, e i mesi passavano,
passavano gli anni e io mi chiedevo se sarebbe andata avanti sempre così, se le speranze, i sogni
inevitabili quando si è giovani, si sarebbero atrofizzati a poco a poco, se la grande occasione
sarebbe venuta o no, e in torno a me vedevo uomini, alcuni della mia età altri molto più anziani,
i quali andavano, andavano, trasportati dallo stesso lento fiume e mi domandavo se anch'io un
giorno non mi sarei trovato nelle stesse condizioni dei colleghi dai capelli bianchi già alla vigilia
della pensione, colleghi oscuri che non avrebbero lasciato dietro di sé che un pallido ricordo
destinato presto a svanire.

La novela, según estas palabras del propio Buzzati, podría haberse situado en el nada estimulante ambiente de la redacción del periódico $\mathrm{y}$, sin embargo, elige una fortaleza militar ¿por qué razón?... Él mismo lo explica más adelante. El ambiente militar, con sus disciplinas y reglas rígidas e inexorables, permitía plasmar el tema de la vida y la esperanza que pasa inútilmente, con mayor evidencia que un periódico; y además, el propio autor confiesa el atractivo que tenía para él la vida militar. Buzzati publicará Il deserto dei Tartari en 1940, el mismo año en el que es enviado como corresponsal de guerra, participando de ese modo en las batallas de Capo Matapan y en la segunda batalla de la Sirte. Este mundo militar con el que el autor se sentía familiarizado y por el que sentía incluso atracción constituyó, por tanto, uno de los elementos fundamentales de inspiración de su novela. Este contexto es el que le servirá a Buzzati para situar un argumento en que el tema del tiempo, una vez más, aparece como eje central de su obra, y que establece, con relación a autores, por ejemplo, como Kafka, una diferencia fundamental en su narrativa (Atchity, 1978: 3). En la elección del tema y en su desarrollo en el argumento reside buena parte de la eficacia de la manifestación de la melancolía, como elemento tonal dominante en toda la obra. Un argumento bien simple y, sin embargo, desde el primer capítulo, está penetrado de un inquietante ambiente de misterio ${ }^{5}$.

La historia de Giovanni Drogo y su viaje al desierto, su larga espera de un acontecimiento que no termina de llegar, la ausencia de enemigo en el horizonte, la reclusión sin sentido que justifique tantos años en una Fortaleza ruinosa y abandonada, ponen en escena la experiencia de un individuo a través de cuyo recorrido se puede vislumbrar la larga y penosa travesía de una vida rutinaria y monótona. En cada una de las fases de este viaje sin retorno que Drogo protagoniza se muestra el paisaje del

4 Dino Buzzati en entrevista con Alberico Sala, citado en la p. 11 del prólogo a la edición de $I l$ deserto dei Tartari (Mondadori, 1970) por la que citaré el texto original en italiano.

5 Para Carlos Suñén, "su estructura es más bien la de un cuento largo que la de una novela", "un argumento apenas, un esbozo, una fábula" (p. vi del prólogo a la edición por la que citaré a partir de este momento los textos en versión castellana de Esther Benítez: El desierto de los tártaros, Madrid, Alianza Editorial, 1990). 
camino hacia la melancolía más radical. A falta de acontecimientos más heroicos, cada una de las acciones que van conformando el fluir de esta vida que se relata está impregnada de una sensación de tristeza cada vez más espesa, frente a la que ni el lector queda inmune. Drogo va experimentando en momentos sucesivos las distintas emociones de un exhaustivo catálogo de la melancolía.

La primera de ellas es la amargura de la partida cuando Drogo se traslada hacia la Fortaleza Bastiani y se despide del hogar materno: «La amargura de dejar por primera vez la vieja casa donde había nacido a las esperanzas (...) pero sobre todo eso (...) un vago presentimiento de cosas fatales, como si estuviera a punto de iniciar un viaje sin retorno» (p. 2) ${ }^{6}$. El ponerse en marcha a la búsqueda de lo desconocido, pues Drogo no sabe muy bien adónde va ni lo que va a encontrar en el momento de iniciar su viaje. Después el miedo, el extrañamiento, el desarraigo y la sensación de soledad que experimenta le hacen encontrarse como «en una tierra extranjera, mundo duro e ingrato» (p. 34) ${ }^{7}$.

Después de la duda y del deseo de huida, opta por quedarse en la Fortaleza, pero pronto le asaltan la ansiedad y la frustración, pues sus expectativas se ven defraudadas ante la inutilidad de la espera. Conoce la desilusión, la primera forma del desengaño cuando una falsa alarma hace brotar la vida en la fortaleza pero en seguida llega la primera desilusión: lo que parece un ejército termina siendo sólo una patrulla.

La nostalgia del «paraíso perdido», la sensación de pérdida es otra de esas emociones de la melancolía. En el capítulo XVII, Drogo va de permiso a la ciudad, pero nada es como antes: «El pequeño mundo de su niñez quedaba encerrado en la oscuridad» ya desde la primera partida. Siente la nostalgia de su propio pasado y aparece en plenitud el tema de «la despedida de un mundo», cuando se hacía la ilusión de conservar intacta «una felicidad desaparecida para siempre, de contener la huida del tiempo» (p. 3) Algo que ya intuyó desde el mismo momento de partir.

Y después, cada vez más escepticismo, desesperanza y obsesión ante el destino: la razón de ser y existir vuelve a materializarse en una espera sin esperanza de la llegada del enemigo: «QQué aburrida vida, ahora! (...) Las esperanzas de antaño, las ilusiones bélicas, la espera del enemigo del norte, no habían sido sino un pretexto para dar sentido a la vida.» (p. 145) ${ }^{9} \mathrm{Y}$ cuando parece que el destino amenaza con cumplirse, Drogo recorre un nuevo tramo de su camino hacia la melancolía. Su compañero Simeoni, con quien comparte la vigilancia del horizonte, le escamotea el tan esperado enfrentamiento con el enemigo, que era ya una obsesión. Conoce así Drogo el desengaño del «otro ser», que le sitúa en una soledad profunda, anímica, interior.

6 “L'amarezza di lasciare per la prima volta la vecchia casa, dove era nato alle speranze (...) ma su tutto (...) come un vago presentimento di cose fatali, quasi egli stesse per cominciare un viaggio senza ritorno." (p. 24).

7 “...in una terra straniera, mondo duro ed ingrato" (p. 62).

8 "Eccolo rinserrato nel buio, il piccolo mondo della sua fanciullezza" (p. 26).

9 "Che vita noiosa, adesso. (...) Pareva evidente che le speranze di un tempo, le illusioni guerriere, l'aspettazione del nemico del nord, non fossero stati che un pretesto per dare un senso alla vita." (p. 191). 
La espera de ese acontecimiento que nunca termina de llegar, inútil, absurda y desesperanzada, en áspera y desoladora soledad, es la imagen pesimista de una vida que espera sin esperanza hasta que le llega la muerte. Muestra la cruel existencia del hombre concebido como ser para la muerte, sin que la razón pueda dar ninguna respuesta válida y sin lugar tampoco para la trascendencia. Como se ha dicho:

In Drogo è l'uomo contemporaneo, che regge l'essistenza su un sentimento sufficientemente razionale, quello dell'attesa dell'Evento: un'attesa, si badi, ragionata, e che un giorno si realizza veramente. La reazione affettiva dello scrittore è pessimistica, e pessimistica dentro i limiti terreni, né varca mai le soglie della trascendenza. (Mazzali, 1973: 11)

\section{CONSTRUCCIÓN DE UN LOCUS MELANCHOLIAE: TIEMPO COMO ES- PACIO Y ESPACIO COMO TIEMPO}

Sin embargo, no solola historia y los temas que plantea son los únicos responsables de cómo El desierto de los tártaros se constituye en el paradigma de un locus melancholiae. Se ha dicho que si hay algo que hace bella esta obra es precisamente la atmósfera de melancolía que en ella se respira (Borelli, 1956: 95). Esta fascinación que ha ejercido y ejerce todavía entre los lectores esta novela se explica por la selección de elementos descriptivos reales, pero sugestivos, que se impregnan de contenido connotativo a través de campos de asociaciones semánticas $\mathrm{y}$, como ya se ha destacado, y no es menos importante, por los detalles que se silencian, por lo que se oculta (Bonifaci, 1982).

El silencio es un motivo constantemente repetido, que aparece como forma de subrayar la soledad y la falta de actividad de la Fortaleza. Es a veces «un extraordinario silencio» $(183)^{10}$, un silencio demasiado grande. Al poco de llegar a Bastiani a Drogo «le impresionó la vastedad del silencio», «el silencio absoluto parecía por fin, incontrovertible señor de la Fortaleza» (pp. 26-27) ${ }^{11}$. El silencio es la presencia callada del misterio, de lo innombrable; en silencio acecha el enemigo (que parece no existir) y en silencio transcurren las horas.

La oscuridad también es una presencia constante. Las brumas que se ciernen siempre sobre el horizonte, que impiden ver qué hay más allá. Son esas «nieblas del norte, que no dejan ver», nieblas que obligan al vigía a forzar la mirada, a buscar en un más allá sobre todo soñado: «algún día el horizonte estará claro» (p. 24) ${ }^{12}$.

Los elementos del paisaje se vuelven altamente connotativos y de gran densidad simbólica, y son responsables de que el sentimiento de melancolía de esta novela adquiera una gran intensidad. Y si hay alguno importante lo serán aquellos que se articulan en torno a este concepto de difícil aprensión que es el del tiempo. A Buzzati no le interesa tanto concretar la causa o el objeto final sobre el que sostener la tensión

10 "Uno straordinario silenzio" (p. 234).

11 "La vastità del silenzio"; "il silenzio assoluto pareva, finalmente, incontrastato signore della Fortezza» (p. 53).

12 "Nebbie del nord che non lasciano vedere" (...) "qualche giorno l'orizzonte sarà pure sereno" (p. $49)$. 
narrativa, sino mostrar un proceso temporal, las reacciones de los personajes durante ese proceso, como después se verá (Atchity, 1978: 12).

La selección de los momentos crepusculares, que sitúan a los personajes en un paisaje exterior ya de por sí melancólico, inducen a un determinado estado de ánimo en Drogo: «Como de ordinario, con la puesta de sol entraba en el ánimo de Drogo una especie de poética animación. Era la hora de las esperanzas» (p. 71) ${ }^{13}$. O bien subrayan el paso del tiempo. El cambio de las estaciones no es un elemento despreciable en la narración; de forma simbólica, y no solamente en un nivel descriptivo, las estaciones se deslizan en paralelismo con la evolución que experimenta la vida en la Fortaleza.

Más que en ningún otro elemento de los que aparecen en la novela, la presencia silenciosa y constante del tiempo se materializa en la imagen de la corriente de un río imparable, inexorable en su avanzar hacia la muerte: «El río del tiempo pasaba sobre la Fortaleza, agrietaba las murallas...». Y ese río es cada vez más veloz y con sus aguas se precipitan las vidas de quienes esperan en el fuerte a que no pase nada:

Entre tanto el tiempo corría, su latido silencioso mide cada vez más precipitado la vida, no podemos ni parar un instante, ni siquiera para una ojeada hacia atrás. ¡Párate! ¡Párate!, quisiéramos gritar, pero comprendemos que es inútil. Todo huye, los hombres, las estaciones, las nubes; y de nada sirve agarrarse a las piedras, resistir en lo alto de un escollo; los dedos cansados se abren, los brazos se aflojan inertes, nos arrastra de nuevo el río, que parece lento pero jamás se para ${ }^{14}$. (p. 167)

La expresión de la fugacidad del tiempo bajo la alegoría del fluir fluvial tiene en este pasaje innegables resonancias clásicas sobre el tema del tempus fugit ${ }^{15}$. Sucede lo mismo cuando Buzzati describe que a Drogo, en la espera, «las horas se le escapaban de entre los dedos antes de que quisiera contarlas» ${ }^{16}$.

Quince largos años se escapan como en un sueño. La experiencia del tiempo es subjetiva, individual, depende de la intuición, y el tiempo se transforma en durée bergsoniana. Pero la imagen del río en la novela responde al tiempo de la naturaleza, al tiempo de la necesidad, al del envejecimiento. Mientras la llanura permanece inmóvil, «el tiempo soplaba», como viento del desierto «mortificando las cosas bellas, y nadie conseguía escaparle» ${ }^{17}$. Durante la espera, Drogo -“Giovanni”- ha envejecido: «El torrente de la vida lo había arrojado ya a un lado, hacia los remansos periféricos, aunque en el fondo ni siquiera contaba cincuenta años» (pp. 175-176). Giovanni Drogo sigue

13 «Como al solito entrava al tramonto nell'animo di Drogo una specie di poetica animazione. Era l'ora delle speranze.» (p. 105).

14 "Il tempo intanto correva, il suo battito silenzioso scandisce sempre più precipitoso la vita, non ci si può fermare neanche un attimo, neppure per un'occhiata indietro. "Ferma, ferma" si vorrebbe gridare, ma si capisce ch'è inutile. Tutto quanto fugge via, gli uomini, le stagioni, le nubi; e non serve aggrapparsi alle pietre, resistere in cima a qualche scoglio, le dita stanche si aprono, le braccia si afflosciano inerti, si è trascinati ancora nel fiume, che pare lento ma non si ferma mai." (p. 216).

15 Sobre este tópico de la literatura clásica y medieval, se puede ver Alonso Monedero (2002).

16 "Le ore gli sfuggivano di sotto prima che lui riuscisse a contarle" (p. 216).

17 "Il tempo soffiava (...) mortificando le cose belle, e nessuno riusciva a sfuggirgli" (p. 225); "il torrente della vita lo aveva gettato oramai da una parte, verso i gorghi periferici, benché in fondo non avesse neppure cinquant'anni" (p. 226). 
esperando, aunque su «esperanza se debilite a cada minuto», y todo carece de sentido para él. Mientras sus viejos amigos contemplan «cómo corre el río de la vida y en el remolino de las multitudes les divierte distinguir a sus propios hijos» ${ }^{18}$, Giovanni ya está infectado, mortalmente «enfermo de tiempo», y de melancolía.

Como en la copla del poeta castellano Jorge Manrique, al final del cauce del río está la desembocadura, el mar. Buzzati continúa hasta ese mismo punto la alegoría del fluir temporal, y justo cuando a Drogo le asalta un pensamiento nuevo, «límpido y brutal», que hasta entonces no había tenido, el de la muerte...

Le pareció que la fuga del tiempo se había detenido, como un encanto roto. El torbellino se había hecho en los últimos tiempos cada vez más intenso, y después repentinamente nada, el mundo se estancaba en horizontal apatía y los relojes corrían inútilmente. El camino de Drogo había terminado; ahora estaba en la solitaria orilla de un mar gris y uniforme, y a su alrededor ni una casa, ni un árbol, ni un hombre, todo así desde tiempo inmemorial ${ }^{19}$. (p. 199, sub. mío)

Había terminado la larga espera: «todos, de un modo u otro, tenían algún motivo, incluso pequeño, para esperar, todos salvo él»»20 La larga espera desesperanzada, la larga e inútil espera, la absurda espera de un acontecimiento que justifique una vida, no es otra que la de la muerte. Y el río del tiempo se cuela por los resquicios de los muros de ese laberinto que es la Fortaleza, del que ninguno de los que ha querido salir lo ha hecho sino ha sido para morir. La historia de esta novela, El desierto de los tártaros, y de su protagonista es, como se ha dicho, antes que nada, «la storie di un uomo nel tempo» (Mazzali, 1973: 10).

\subsection{La Fortaleza como «laberinto de tiempo»}

La cuestión importante es cómo el autor de la fábula es capaz de trasladar narrativamente la sensación de tiempo a través de las sensaciones espaciales: de qué forma tan meritoria el estatismo de un entorno cerrado se transforma en una metáfora espacial para traducir la angustiosa atmósfera del paso del tiempo. Es justamente lo contrario de lo que opina Juan Carlos Suñén, cuando dice que la Fortaleza es el espacio simbólico del no-tiempo, el lugar de la muerte o de la eternidad, habida cuenta de que ninguno de los personajes muere dentro de ella: ni Angustina, ni Lazzari -el soldado que ignora la contraseña para volver a entrar en ella-, ni Ortiz, ni Drogo.

Sin embargo, es ahí dentro, en ese espacio sin salida, entre las paredes de la Fortaleza, donde los personajes van dejándose morir o, si se prefiere, va esperando la muerte cada uno de sus habitantes. La vida allí parece no transcurrir a causa de

18 "Come corra il fiume della vita en el turbina della moltitudine si divertono a distinguere i propri figli" (p. 230).

19 “Gli parve che la fuga del tempo si fosse fermata, come per rotto incanto. Il vortice si era fatto negli ultimi tempi sempre più intenso, poi improvvisamente più nulla, il mondo ristagnava in una orizzontale apatia e gli orologi correvano inutilmente. La strada di Drogo era finita; eccolo ora sulla solitaria riva di un mare grigio e uniforme, e attorno né una casa né un albero né un uomo, tutto così da immemorabile tempo." (p. 252).

20 "Ttutti in un modo o nell'altro avevano qualche motivo, anche piccolo, per sperare, tutti fuori che lui" (p. 251). 
la repetición y de la monotonía, pero sin embargo, avanza inexorable el paso de la destrucción del tiempo entre las piedras de sus muros. En la Fortaleza los hombres viven como en un refugio la espera de ese enfrentamiento letal. En el reducido espacio interior, el soldado se va entrenando en la espera de la confrontación que parece que nunca acaba de llegar, mientras se va debilitando su energía vital.

La Fortaleza es, por tanto, a la vez que un espacio real, un espacio interior en que la falta de acción aumenta la conciencia, y la gran importancia de este símbolo, que eclipsa por momentos al del desierto, se revela a lo largo de la lectura, cuando percibimos que adquiere casi un alma y que tiene incluso «respiración» (p. 45) ${ }^{21}$.

Casi todas las páginas de la obra transcurren en el interior de sus muros. No es casualidad que la obra fuera a llevar en origen precisamente el título de La fortezza. Como un espejismo de la conciencia, en mitad del desierto, la Fortaleza Bastiani va cambiando su imagen, metamorfoseándose según el estado de ánimo de quien la habita o de quien la contempla. La primera impresión no deja lugar a dudas sobre la sensación de melancolía y tristeza que provoca en el alma: «La Fortaleza es melancólica, no hay pueblos cercanos, no hay ninguna diversión, ninguna alegría» (p. 35) 22 .

Es grandiosa, pero «la sordidez de aquellas murallas, el aire vago de castigo y exilio» hace que los hombres se sientan en ella «ajenos y absurdos» (p. 35) ${ }^{23}$. Lagorio la siente como «una obsesión»; en otros momentos aparece como el «castillo encantado» perfecto como escenario para la muerte de Angustina, un verdadero príncipe (p. $114)^{24}$.

La primera vez que Drogo se para a contemplarla siente su inexplicable atractivo, la fuerza de su misterio, tan complicada e inmensa. Ese mismo poder de fascinación ejerce sobre el capitán Ortiz. Pero poco a poco va transformándose en una horrible prisión, y sus habitantes se sienten «aprisionados aquí dentro» (p. 120): «Las murallas ya no son un refugio hospitalario, sino que dan una impresión de cárcel» ${ }^{25}$ (p. 123).

En el segundo viaje de regreso, al encontrarse Drogo con ella le pareció que «ya no encerraba, como la primera vez, inquietantes secretos. No era en realidad más que un cuartel limítrofe, una ridícula bicoca... ». Esta es la visión consecuente con la experiencia de frustración que ha sufrido el protagonista, una visión que ha dejado de ser fascinante, para ser desengañada:

21 "Respiro" (p. 45).

22 “La Fortezza è malinconica, non ci sono paesi vicini, non c'è nessun divertimento e nessuna allegria” (p. 63).

23 «lo squallore di quelle mura, quell'aria vaga di punizione ed esilio» hace que los hombres se sientan en ella «stranieri ed assurdi» (p. 64).

24 “Un'ossessione" (p. 82); “castello incantato" (p. 156).

25 "Imprigionati qua dentro" (pp. 162-163); “le mura non sono più riparo ospitale ma danno l'impressione di carcere" (pp. 166-167). 
Vastos sectores de murallas estaban sin custodiar y por allí penetraban los pensamientos de oscuridad, la tristeza de estar solo. En realidad el viejo fuerte era como una isla abandonada, circundado por territorios vacíos ${ }^{26}$. (p. 176)

La Fortaleza no es el espacio del no-tiempo, dentro de ella puede sentirse el transcurso del tiempo cada vez más veloz. Incluso cuando la monotonía disfraza el inexorable fluir de la vida:

El río del tiempo pasaba sobre la Fortaleza, agrietaba las murallas, arrastraba hacia abajo polvo y fragmentos de piedra, limaba los peldaños y las cadenas, pero sobre Drogo pasaba en vano; aún no había conseguido engancharlo en su huida ${ }^{27}$. (p. 65)

Pero el aún, delata que inevitablemente llegará a «engancharlo en su huida». La fortificación pretende ser un refugio frente al tiempo, un lugar a salvo del enemigo, pero se trata de una vana pretensión:

La Fortaleza, en cambio, encerraba pobres hombres, indefensos contra la obra del tiempo, cuyo último término se aproximaba. Fechas que antaño había parecido inverosímiles, de tan remotas, asomaban ahora inesperadamente por el cercano horizonte, recordando los duros plazos de la vida. $(\text { p. } 177)^{28}$

La Fortaleza no es un cerco inexpugnable para el enemigo, el tiempo, sino una prisión, en que cada hombre persigue «a través de los laberintos de la fortificación» ${ }^{29}$ la esperada confrontación con el enemigo.

\subsection{La acedia dentro del laberinto}

«La melancolía es la enfermedad del tiempo», así la define Minkowski, como recoge Carlos Gurméndez en «Melancolía y tiempo»30 (1990: 75 y ss.):

«Lo más frecuente es el melancólico que no sabe qué hacer con el tiempo que vive, y lo deja pasar sin poder contenerlo, (...) como si no pasase nunca nada (...) Entonces no hay nada qué hacer, no se espera ningún acontecimiento ni tampoco la posibilidad de recordar, porque lo que ha sido se desvaneció por completo» (p. 77).

Aunque se ha dicho que esta es novela de un solo personaje (Borelli, 1956: 93), este no está solo en el interior de la Fortaleza Bastiani. Dentro de ella, todos están «enfermos de melancolía», en mayor o menor medida, de una forma o de otra, todos están afectados por esa especie de enfermedad o locura, y los rasgos de sus personalidades muestran este efecto de la espera y del hastío. Son seres que vagan años

26 "Vasti settori di mura erano incustoditi e di là penetravano i pensieri del buio, la tristezza di essere soli. Come una sperduta isola era infatti il vecchio Forte, attorniato da territori vuoti" (p. 226).

27 "Il fiume del tempo passava sopra la Fortezza, screpolava le mura, trascinava in basso polvere e frammenti di pietra, limava gli scalini e le catene, ma su Drogo passava invano; non era ancora riuscito ad agganciarlo nella sua fuga" (pp. 98-99).

28 "La Fortezza invece conteneva poveri uomini, indifesi contro il lavoro del tempo, e il cui termine ultimo si avvicinava. Date che una volta erano parse inverosimili, da tanto lontane, si affacciavano ora improvvisamente al vicino orizzonte, ricordando le dure scadenze della vita." (p. 227)

29 “Attraverso i laberinti delle fortificazioni” (p. 226).

30 Sigo este estudio de la melancolía de Carlos Gurméndez para el análisis de los tipos de melancólicos que se dan en los personajes de esta obra de Buzzati. 
y años por los pasajes de la fortaleza, y entre cuyos «muros amarillos» van perdiendo las ilusiones, los deseos, la esperanza, el tiempo de vivir, sin que sean capaces de encontrar, enfermos y desgastados, el hilo que les conduzca a la salida de ese laberinto. Todos ellos muestran los distintos rostros de una misma enfermedad. Buzzati los ha situado a modo de espejos en los pasadizos dentro del mismo laberinto, de forma que Drogo, su protagonista, no pueda evitar mirarse en ellos. Todos le devuelven el mismo malestar, a un mismo reducto donde solo queda la nada melancólica. Cada uno de los habitantes de ese espacio parece mostrar un camino alternativo, sin embargo, como en los laberintos de caminos alternativos, unos conducen a otros, devolviéndonos una y otra vez a las mismas encrucijadas.

Uno de los primeros casos de la novela, el sastre Prosdocimo: lleva quince años en el fuerte, pero sigue diciendo que está en él «de forma absolutamente provisional» (p. 43). El hermano del sastre le advierte a Drogo de que se vaya pronto, antes de coger la «manía» de los demás, «una especie de enfermedad», «mientras aún está a tiempo...» (p. 44) ${ }^{31}$. Incluso el médico, Ferdinando Rovina, que lleva también veinticinco años en el fuerte. También él habla de enfermar, aunque lo haga reconociendo el valor metafórico de sus palabras:

«Uno a uno se van todos (...) acabaremos por quedarnos sólo los viejos (...) Hasta Morel, apuesto, el año que viene tendrá que bajar a la ciudad a curarse. Hasta él, apuesto, acabará por enfermar.... ${ }^{32}$. (p. 56)

Otros personajes con mayor protagonismo conforman un interesante abanico de «casos clínicos» en los que la afección de la enfermedad de Saturno muestra distintos síntomas y personalidades. Ellos son los reflejos que repiten una y otra vez un mismo rostro, los pasadizos que conducen una y otra vez a un mismo lugar del laberinto en que se convierte la vida dentro de la Fortaleza Bastiani.

\subsubsection{El capitán Ortiz, el «melancólico abúlico»}

El capitán Ortiz es la primera persona con la que Drogo se encuentra cuando parte hacia la Fortaleza la primera vez y todavía no sabe dónde situarla; su actitud es contemplativa, de lúcida fascinación:

Ortiz se había quedado inmóvil y miraba intensamente las amarillas murallas. Sí, él, que vivía allí desde hacía dieciocho años, las contemplaba, casi hechizado, como si volviera a ver un prodigio. Parecía no cansarse de remirarlas y una vaga sonrisa, de alegría y tristeza al tiempo, iluminaba lentamente su rostro ${ }^{33}$. (p. 16)

31 "In via as-so-lu-ta-men-te prov-vi-so-ria" (p. 72); "una specie di malattia", "stia attento finché è in tempo..." (p. 73).

32 "Ad uno ad uno ve ne andate tutti. (...) Finiremo per restare soltanto noi vecchi (...) Anche Morel, scommetto, quest'altr'anno dovrà scendere in città a farsi curare. Anche lui, scommetto, finirà per ammalarsi..." (p. 87).

33 "Anche Ortiz era rimasto immobile e fissava intensamente le gialle mura. Sì, lui che ci viveva da diciott'anni, le contemplava, quasi ammaliato, come se rivedesse un prodigio. Pareva che non si stancasse di rimirarle e un vago sorriso insieme di gioia e di tristezza illuminava lentamente il suo volto. » ( $\mathrm{p}$. 40). 
Es la leve y triste sonrisa de la melancolía que aparecerá en distintas ocasiones, en los rostros de varios de los personajes de esta historia, en Angustina, y en el mismo Drogo cuando se ve ante su propia muerte. La sonrisa del que se sabe más allá de la tristeza de la vida, del que observa entre irónico y distanciado el sinsentido de la existencia.

Este encuentro tiene un valor proyectivo, de verdadera prolepsis que se pone de manifiesto al final de la novela, cuando un encuentro similar se repite, en perfecto paralelismo, esta vez entre Giovanni Drogo (que ha tomado ya el relevo a Ortiz) y un nuevo soldado que llega para incorporarse a la Fortaleza Bastiani, Moro. Éste, cual nuevo Giovanni, nos retrotrae el principio de la historia, en una estructura premeditadamente circular. La historia comienza a repetirse.

El capitán es la presencia más solidaria y sensible a los miedos y a la angustia de Drogo. En él encuentra Drogo el espejo de sí mismo, la fraterna solidaridad de quien se siente unido en un mismo destino, víctima del mismo paso del tiempo: «El propio comandante Ortiz, que andaba ya por los cincuenta años, asistía apático a la fuga de las semanas y de los meses. Ahora había renunciado a sus grandes esperanzas...» ${ }^{34}$ (p. 160).

En esta renuncia está la clave de una existencia que se deja llevar por la inercia. Más adelante Ortiz le confiesa a Drogo: «He sabido contentarme. Años tras año he

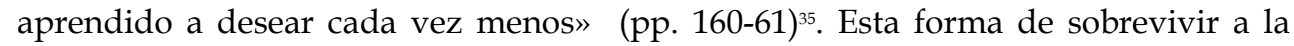
angustia temporal es la de la melancolía abúlica, una manera muy de Schopenhauer de evitar el dolor de vivir, mediante la anulación de la voluntad. La sombra de Kierkegaard se cierne en esta forma de acedia moderna, para quien la melancolía es una debilidad, un pecado, es el pecado de no querer profunda y sinceramente, la inhibición, como ha estudiado M. C. Lambote (1999: 50).

La sintonía que hay entre Ortiz y Drogo se traduce en la simpatía y la amistad que siente éste por el comandante. Cuando Drogo parte de permiso, al abandonar la Fortaleza, dice para sí:

«Adiós, comandante Ortiz, melancólico amigo» ${ }^{36}$ porque éste ha renunciado, y ya no es capaz de apartase de la pequeña fortificación. Pero cuando Drogo abandona a su vez la Fortaleza, todos lo ven ya como un viejo «sin deseos ni remordimientos» ${ }^{37}$ (p. 197).

\subsubsection{El sargento Tronk, el «maníaco-melancólico»}

La rutina militar emerge como centro de atención en los primeros capítulos de la novela (sobre todo en el capítulo V) y es descrita pormenorizadamente, como la actitud del personaje que encarna esta «manía de los reglamentos»:

34 “Lo stesso maggiore Ortiz, ch'era già sulla cinquantina, assisteva apatico alla fuga delle settimane e dei mesi. Egli aveva oramai rinunciato alle grande speranze..." (p. 209).

35 "Ho saputo accontentarmi. (...) Anno per anno ho imparato a desiderare sempre meno" (p. 210).

36 “Addio Maggiore Ortiz, melanconico amico" (p. 168).

37 "Senza desideri o rimorsi" (p. 249). 
El relevo con los centinelas salientes se había producido con meticulosa precisión ante los ojos del sargento primero Tronk, especialista en los reglamentos. Tronk llevaba veintidós años en la Fortaleza y ahora ya ni siquiera se movía de ella en los períodos de permiso. Nadie conocía como él cada rincón de la fortificación... Cuando él estaba de servicio, los centinelas no abandonaban ni un instante el fusil, no se apoyaban en las murallas y hasta evitaban detenerse, porque las paradas sólo estaban permitidas en casos excepcionales; Tronk no dormía en toda la noche y vagaba con pasos silenciosos por el camino de ronda, haciéndolos estremecerse. “¿Quién va? ¿Quién va?", preguntaban los centinelas... ${ }^{38}$. (pp. 30-31)

Cuando Drogo, en los momentos de nostalgia, escribe a su madre, contándole de su vida en la Fortaleza, decide, para no causarle amargura, no hablarle de las «manías de Tronk»»9 (p. 36), en donde ya aparece claramente esbozado ese carácter maniático que adquiere en este antipático personaje el sentimiento de melancolía que produce la espera. Todos los personajes están pendientes de una vana esperanza, y en relación con ella es como alcanza su verdadero sentido ese estricto cumplimiento del reglamento del sargento Tronk; el narrador lo refleja así unas páginas más adelante:

Tronk seguía los artículos del reglamento, la disciplina matemática, el orgullo de la responsabilidad escrupulosa, y se hacía la ilusión de que eso le bastaba. Mas si le hubieran dicho: siempre así mientras vivas, todo igual hasta el final, también él habría despertado. Imposible, habría dicho. Algo distinto tendrá que venir, algo verdaderamente digno, como para poder decir: ahora, aunque haya acabado, paciencia $^{40}$. (p. 46)

Carlos Gurméndez (1990: 43) se refiere en su monografía sobre este tema a esta forma de melancolía, como «manía burguesa» si no en términos de «disciplina matemática» sí en los de «cálculo exacto»:

El maniático se afana simplemente por llevar a cabo lo que ha emprendido, y se siente satisfecho cuando ha cumplido a fondo la tarea que se propuso. El cálculo exacto, la racionalidad formal, propia del orden burgués, define al maníaco-melancólico.

Esta «manía burguesa» me parece extrapolable a la que se produce dentro del orden militar en el caso del sargento Tronk porque consiste en unos mismos síntomas de actividad exagerada, carente de mesura y equilibrio, de raíz tan melancólica como la indolente pasividad. A juicio de Gurméndez ese dinamismo, ese afán de movimiento es una respuesta al sentimiento de abandono, de «ser-ahí», como decía Heidegger, que posee a todo ser humano. Este tipo de melancólico refleja esa pasividad del ser, de la existencia -que también refleja la vida en la Fortaleza- y se manifiesta en ese afán de

38 "Il cambio con le sentinelle smontanti era avvenuto con meticulosa precisione sotto gli occhi del sergente maggiore Tronk, specialista dei regolamenti. Tronk era alla Fortezza da ventidue anni e oramai non se ne muoveva più neppure nei periodi di licenza. Nessuno conosceva come lui ogni angolo della fortificazione (...). Quando lui era di servizio, le sentinelle non abbandonavano per un istante il fucile, non si appoggiavano ai muri ed evitavano persino di fermarsi, perché le soste erano concesse solo in via eccezionale; pero tutta la notte Tronk non dormiva e a passi silenziosi si aggirava peri l camino di ronda, facendole trasalire. «Chi va là, chi va là?» chiedevano le sentinelle...» (pp. 57-58).

39 “Manie de Tronk» (p. 64).

40 “Tronk inseguiva gli articoli del regolamento, la disciplina matematica, l'orgoglio della responsabilità scrupolosa, e si illudeva che ciò gli bastasse. Pure se gli avessero detto: sempre così fino che vivi, tutto uguale fino in fondo, anche lui si sarebbe svegliato. Impossibile, avrebbe detto. Qualche cosa di diverso dovrà pur venire, qualche cosa di veramente degno, da poter dire: adesso, anche se è finita, pazienza." (p. 76). 
orden, pulcritud y exactitud llevados a extremos maníacos. Drogo también cae en esa forma de disuadir a la melancolía:

Drogo se habría marchado igualmente; pero estaban ya en él el entorpecimiento de los hábitos, la vanidad militar, el amor doméstico a los muros cotidianos. Cuatro meses habían bastado para enviscarlo en el monótono ritmo del servicio. En hábito se había convertido el turno de guardia... poco a poco había aprendido bien las reglas, los modismos, las manías de sus superiores... hasta Tronk se había dado cuenta de los serio y escrupuloso que era Drogo, casi le había tomado cariño $0^{41}$. (p. 58)

La evolución de Drogo y el contraste con la que fuera su primera impresión del sargento es patente, y Buzzati dedica varios párrafos a describir detalladamente hasta qué punto los hábitos cotidianos han captado a Giovanni Drogo. Todavía la última vez que regresa a la Fortaleza, al puesto de siempre, y se siente resignado a esperar a nada, «en el fondo de su alma hay incluso una tímida complacencia por poder volver tal cual a sus viejos hábitos» (p. 143) ${ }^{42}$.

\subsubsection{Angustina, el «melancólico temperamental»}

Entre los nuevos amigos de Drogo, Angustina destaca por su actitud, su compostura, sus gestos, todo en él, incluido su nombre, nos habla de un personaje esencialmente melancólico, desde el primer momento: «Angustina era pálido y estaba sentado con su perenne aire de despego, como si no se interesara, como si estuviera allí por puro azar». Y poco más adelante: «su uniforme azul, desteñido por el sol, se destacaba entre los otros por una indefinible y negligente elegancia» ${ }^{43}$ (p. 47).

Su actitud distinguida y original, desinteresada hacia la vida, su desapego hacia las cosas, su aire de aburrimiento, su constitución débil y enfermiza, su talante pensativo, su rostro "cargado de inconfesado cansancio» lo configuran como el personaje modelo del hombre melancólico.

Angustina, en el capítulo XI, protagoniza un sueño de Drogo. El sueño se desarrolla en un ambiente fantasmagórico: Angustina es guiado en fúnebre cortejo de fantasmas o espíritus procedentes del abismo, en una bella carroza, hacia un espacio celestial, hacia la luna. El rostro de Angustina no pierde la sonrisa mientras se aleja en la noche, "con nobleza casi inhumana" ${ }^{44}$ y desaparece sin echar la vista a lo que queda atrás.

41 “Drogo sarebbe ugualmente partito; ma c'era già in lui il torpore delle abitudine, la vanità militare, l'amore domestico per le quotidiane mura. Al monotono ritmo del servizio, quattro mesi erano bastati per invischiarlo. Abitudine era diventato per lui il turno di guardia (...); a poco a poco aveva imparato bene le regole, i modi di dire, le manie dei superiori (...) persino Tronk si era accorto come Drogo fosse serio e scrupoloso, gli si era quasi affezionato." (pp. 90-91).

42 “Nel fondo dell'animo c'è perfino la pavida compiacenza (...) di poter rientrare tale e quale nelle vecchie abitudini" (p. 189).

43 "Angustina era pallido e sedeva con la sua perenne aria di distacco, come se non si interessasse affatto di loro, fosse lì per un puro caso" (p. 77); "La sua uniforme azzurra, stinta dal sole, spiccava fra le altre per un'indefinibile trasandata eleganza" (p. 78).

44 “Con nobiltà quasi inumana" (p.158). 
En el capítulo XV se confirma que ese sueño era una premonición de la muerte de Angustina, que termina muriendo con una sonrisa congelada en los labios. Angustina demuestra -en la larga caminata que termina con su vida- una extraordinaria resistencia ante el dolor, y por su actitud muestra una nobleza de carácter, una forma de heroicidad poco frecuente. Angustina adopta la personalidad del melancólico en cuanto un ser original y extraordinario, y en su muerte conserva «toda la nobleza y una suma elegancia», como el "príncipe Sebastián» del viejo cuadro de la Fortaleza:

Ahora Angustina (...) se estaba pareciendo al príncipe Sebastián herido en el corazón del bosque;
Angustina no tenía como él, una reluciente coraza, ni a sus pies yacía el yelmo sanguinolento,
ni la espada rota; no apoyaba la espalda en un tronco, sino en un duro peñasco; no le iluminaba
la frente el último rayo de sol, sino solamente una débil linterna. Pero se le parecía muchísimo,
idéntica la posición de los miembros, idéntico el plegado del capote, idéntica aquella expresión
de cansancio definitivo ${ }^{45}$. (p. 115)

Como Drogo en su propia muerte, Angustina, un personaje perdedor, un antihéroe, manifiesta toda su dignidad en su desprendimiento del mundo, en su aceptación del morir.

\subsection{Giovanni Drogo: en el centro del laberinto}

Al principio «los días parecen largos y tranquilos, el sol resplandece alto en el cielo y parece que nunca tiene ganas de caer hacia poniente» ${ }^{46}$ (p. 38). Los días son iguales y Drogo siente que tiene mucho tiempo por delante. Su existencia parece detenida; pero se trata, una vez más, de un «espejismo». El personaje protagonista va adquiriendo similares síntomas de la misma dolencia. En una novela que se va revelando como paradigma del síndrome de la melancolía contemporánea, su protagonista termina siendo la víctima mortal de la enfermedad. Reúne en sí mismo una larga lista de indicios, de síntomas, circunstancias, actitudes, sentimientos, o sensaciones que lo configuran también a él como un personaje paradigma de la acedia de nuestro tiempo.

La larga lista de sus «síntomas» se asienta, en primer lugar, en su tristeza natural. Cuando Giovanni Drogo es nombrado oficial en el principio de la novela y le conceden el destino que llevaba largo tiempo deseando, se mira en el espejo «sin encontrar la alegría que había esperado», sólo «una cansada sonrisa en su rostro, al que en vano había tratado de amar» (pp. 1-2) ${ }^{47}$. Esta tristeza natural a su carácter parece ligarse con un cierto desprecio de sí mismo, que, según Freud, procede del hecho de

45 “Ora Angustina (...) andava assomigliando al Principe Sebastiano ferito nel cuore della foresta ; Angustina non aveva come lui la lucente corazza, né ai suoi piedi giaceva l'elmo sanguinolento, né la spada spezzata; non appoggiava la schiena a un tronco bensì a un duro macigno; non l'ultimo raggio del sole lo illuminava in fronte ma soltanto una fioca lanterna. Eppure gli assomigliava moltissimo, identica la posizione delle membra, identico il drappeggio della mantella, identica quell'espressione di stanchezza definitiva." (pp. 157-158).

46 "Le giornate sono lunghe e tranquille, il sole risplende alto nel cielo e sembra non abbia mai voglia di calare al tramonto" (p. 67).

47 "Senza trovare la leticia che aveva sperato», sólo «uno stentato sorriso sul proprio volto, che invano aveva cercato di amare" (pp. 23-24). 
no haber sabido la persona convertirse en objeto de amor de sí mismo, en la etapa del narcisismo (Lambote, 1999).

a. Su soledad. Después de la excitación del viaje se siente "triste y desamparado" y comienza a conocer en serio qué es la soledad. La sensación de desamparo es tan grande que tiene conciencia de que «probablemente tampoco en todo el mundo había un alma que pensase en Drogo» (p. 25), ni siquiera su madre. "Y se sentía solo como nunca en su vida», por eso busca alivio en las cartas que le escribe a su madre porque se siente «completamente solo» ${ }^{48}$.

Esta soledad es en Drogo una dolencia que le acompaña en todo momento y que su estancia en el desierto no hace más que acentuar. Al volver a su casa de permiso se siente de nuevo solo y vaga por la ciudad en solitario. La falta de comunicación es casi total. Y la sensación de desamor llega en él hasta la médula: «dopo tutto egli era solo al mondo, e fuor che lui stesso nessun altro lo amava» (p. 250). En radical soledad transcurre su aburrida e insulsa vida, y en soledad radical se produce su abandono de la Fortaleza y su muerte.

Es en todo momento el sentimiento del ser humano abandonado en soledad en el mundo y ante su mortal destino. La ausencia del amor del otro, de la comprensión del otro y de la comunicación con los otros es sencillamente un anticipo de la soledad de la muerte.

b. Los altibajos de ánimo. Son característicos del carácter melancólico, como lo es su indecisión. Al poco de llegar a la Fortaleza, después de la excitación del viaje le asalta a Drogo la tristeza, y cae en un estado de abatimiento; poco después, cuando, tras dudarlo, decide quedarse en la Fortaleza, sentirá que «la exaltación se mudaba en una extraña pena, próxima a la felicidad» ${ }^{49}$ (p. 71). Más adelante, cuando vuelve a la casa de su madre, «sentía mudarse la felicidad en tristeza desganada $»^{50}$ (p. 127).

c. La sensación de extrañamiento. Esta sensación le asalta en varias ocasiones. Al llegar a la Fortaleza «le pareció encontrarse entre hombres de otra raza, en una tierra extranjera» (p. 34); entre los trajes del sastre, observa que «todo alrededor colgaban flojos, con siniestro abandono de ahorcados» ${ }^{51}$ (p. 42). También se siente extranjero al volver a su casa, a su pasado; sus pasos se han vuelto «ajenos» incluso para su madre.

\footnotetext{
48 "Probabilmente anche in tutto il mondo non c'era un'anima che pensasse a Drogo" (p. 51). "E si sentiva solo come mai nella vita" (p. 52); “completamente solo" (p. 63).

49 “L'esaltazione tramutarsi in una strana pena, prossima alla felicità" (p. 89).

50 "Sentiva mutarsi la felicità in tristezza svogliata" (p. 170).

51 "Gli parve di trovarsi fra uomini di altra razza, in una terra straniera, mondo duro ed ingrato" (p. 62); "tutt'attorno pendevano flosci, con sinistro abbandono da impiccati, decine e decine di uniformi, pastrani e mantelli" (p. 71).
} 
d. La sensación de «déjà vu». Ante la visión del desierto, la primera vez que lo observa se pregunta:

¿Dónde había visto ya Drogo aquel mundo? ¿Lo había vivido quizá en sueños o lo había construido al leer alguna vieja fábula? Le parecía reconocer las bajas rocas caídas, el valle tortuoso sin árboles ni verde... Ecos profundísimos de su alma se había despertado, y él no sabía entenderlos ${ }^{52}$. (p. 24)

e. Su actitud contemplativa y soñadora. Durante la espera del enemigo, allí, encerrado en la Fortaleza, se dispone de todo el tiempo del mundo, mientras no pasa nada. Son muy numerosos los momentos en que el protagonista aparece contemplando el paisaje, atraído por la inmensa llanura o por el estático horizonte: «Inmóvil, miraba fijamente las barreras de rocas del frente, las impenetrables lejanías del norte... $»^{53}$ (p. 61).

Como forma de entretener el aburrido paso de las horas, Drogo también se entrega a la ensoñación. A veces sueña despierto con otros lugares de paz y sosiego (ese «palacio junto al mar»); otras veces es el insomnio, otro de los rasgos del melancólico, el que le sitúa en una vigilia muy lúcida:

Le pareció que un entorpecimiento repentino lo arrastraba al sueño. Pero estaba demasiado consciente. Una barahúnda de imágenes, como de sueño, pasaron ante él, comenzaban incluso a formar una historia; pero tras unos instantes advirtió que estaba aún despierto ${ }^{54}$ (p. 26).

Otras veces sus sueños son reveladores, premonitorios, como el de la muerte de su compañero Angustina.

f. Su «manía del reglamento». Ya se ha comentado, al hablar de las manías del sargento Tronk, cómo Drogo se va contagiando de estos hábitos, por lo que el estricto cumplimiento de reglas se vuelve familiar, doméstico y parece justificar la inutilidad de las horas.

g. El componente supersticioso de su personalidad. A pesar de que se dice al principio de la novela que no era especialmente supersticioso, sin embargo en ocasiones reacciona con «supersticioso temor» (p. 169) $)^{55}$. La resistencia a abandonar la Fortaleza, el mundo que había prestado refugio a su existencia, es justificada por Drogo con explicaciones supersticiosas, que también apuntan a un rasgo definidor de su personalidad melancólica: «Una oscura superstición le decía que si abandonaba ahora la Fortaleza, por enfermedad, jamás

52 “Dove mai Drogo aveva già visto quel mondo? C'era forse vissuto in sogno o l'aveva costruito leggendo qualche antica fiaba? Gli pareva di riconoscerle, le basse rupi in rovina, la valle tortuosa senza piante né verde... Echi profondissimi dell'animo suo si erano ridestati e lui non li sapeva capire" (p. 49).

53 “Inmobile egli fissava le barriere di rupi dirimpetto, le impenetrabili lontananze del nord..." (p. 61).

54 "Gli parve che un torpore improvviso lo trascinasse nel sonno. Ma ne aveva troppo coscienza. Una baraonda di immagini, quasi di sogno, gli passarono davanti, cominciavano persino a formare una storia; ma dopo qualche istante si accorse di essere ancora sveglio." (pp. 52-52)

55 “Superstiziosa paura” (p. 218). 
regresaría» (p. 181). Se nos hace saber, hacia el final de la novela, que «Drogo no había querido cambiar de habitación después de su nombramiento como comandante, temiendo que eso le trajera mala suerte» (p. 183) ${ }^{56}$.

h. Su nostalgia del «paraíso perdido». Al Giovanni Drogo joven, la soledad es todavía grata: «Saboreaba con orgullo su decisión de quedarse, el amargo gusto de abandonar las alegrías menudas y seguras por un gran bien a largo e inseguro plazo (...) Tenía mucho tiempo por delante. Todo lo bueno de la vida parecía esperarle. ¿Qué necesidad tenía de apresurarse?» (p.61) ${ }^{57}$. Pero, poco a poco, se va convirtiendo en el de una historia que es toda ella en sí misma una larga despedida, de la juventud, del mundo, de los compañeros de fatigas, de la vida. Desde las primeras páginas aparece despidiéndose para salir a un «viaje sin retorno» ${ }^{58}$. Tras la emoción de despedirse de su madre, su primera despedida dentro de una larga serie, se esconde el miedo, o «un vago presentimiento de cosas fatales»: «en el fondo -se dio cuenta Giovanni Drogo- el tiempo mejor, la primera juventud, probablemente había acabado» ${ }^{59}$.

Después vinieron otras pérdidas. La despedida definitiva de su pasado, de su infancia, la nostalgia de ese mundo perdido y clausurado para siempre, el de la infancia. También tuvo que despedirse de su primer amor, María:

Drogo comprendía que aún quería a María y que amaba su mundo; pero todas las cosas que alimentaban su vida de antes se habían quedado lejos; un mundo ajeno, donde su puesto había sido ocupado fácilmente. Y lo consideraba ahora desde fuera, aunque con nostalgia; (...) retroceder habría sido estúpido e inútil ${ }^{60}$. (p. 136)

Lo vemos despedirse de las únicas personas con la que simpatiza en la Fortaleza, su amigo Angustina porque muere y el capitán Ortiz cuando abandona el fuerte, a sus cincuenta y cuatro años. Éste último es uno de los momentos de más intensa melancolía de la novela. Pero es cuando se encuentra con el nuevo soldado Moro, y rememora su

56 “Una oscura superstizione gli diceva che se avesse lasciato adesso la Fortezza, per malattia, mai più sarebbe ritornato" (p. 232); "non aveva voluto cambiare di camera, quasi temendo che non gli avrebbe portato fortuna" (p. 234).

57 "Assaporava con orgoglio la sua determinazione di restare, l'amaro gusto di lasciare le piccole sicure gioie per un grande bene a lunga e incerta scadenza (...) Egli aveva tanto tempo davanti. Tutto il buono della vita pareva aspettarlo. Che bisogno c'era di affanarsi?" (p. 94).

58 "Viaggio senza ritorno" (p. 24).

59 "In fondo -si accorse Giovanni Drogo- il tempo migliore, la prima giovinezza, era probabilmente finito" (p. 24).

60 "Drogo capiva di voler bene ancora a Maria e di amare il suo mondo; ma tutte le cose che nutrivano la sua vita di un tempo si erano fatte lontane; un mondo di altri dove il suo posto era stato facilmente occupato. E lo considerava oramai dal di fuori, pur con rimpianto; (...) tornare indietro sarebbe stato stupido e vano." (p. 181). 
primer encuentro con Ortiz, cuando siente que «un nudo le apretaba el corazón: adiós sueños del tiempo lejano, adiós hermosas cosas de la vida» ${ }^{61}$ (p. 174).

Al final asistimos a la última, quizá la más triste de todas las despedidas, al abandonar la Fortaleza Bastiani para siempre. «Adiós, Fortaleza», se dijo:

Los ojos de Drogo miraban como jamás las amarillentas paredes de la Fortaleza, los perfiles geométricos de casamatas y polvorines. Lágrimas lentas y amarguísimas caían por la piel arrugada, todo acababa miserablemente y no quedaba nada que decir ${ }^{62}$.(p. 195).

i. La abulia. La resignación, la pasividad, la falta de deseo o la renuncia producen ese estado abúlico del melancólico, al que poco a poco van llegando los habitantes de la Fortaleza. A Drogo, como al capitán Ortiz (ver 2.3.1), no le queda otro remedio para superar la angustia del tiempo y sobrevivir, que dar cobijo a la apatía, ese sentimiento que convierte el tormento de la espera en hastío vital.

j. Los síntomas de enfermo melancólico: trastornos de hígado, diarreas, vértigo. La espera en el tiempo, la inactividad, «la oscura angustia de las horas que pasan» ${ }^{63}$ llegan a enfermar a Giovanni Drogo. Es la espera en el tiempo la que termina manifestándose en signos físicos. En principio, el cuerpo de Drogo muestra signos de envejecimiento: las arrugas, el pelo gris, el paso menos ligero..., pero a medida que se debilita su esperanza aparecen otros síntomas inequívocos: «Después empezó a adelgazar, el rostro se le puso de un triste color amarillo, los músculos se aflojaron. Trastornos del hígado, decía el doctor Rovina, ya viejísimo» (p.180) ${ }^{64}$. Esa falta de tono, que comenzaba con cansancio desde que se despertaba por la mañana, esa pérdida de energías, «los dolores de cabeza y las penosas diarreas ${ }^{65}$ son síntomas que evidencian que Drogo padece el mal de la melancolía, en un nivel somático y no sólo psicológico o anímico.

Es realmente una llamativa sorpresa la que aporta Buzzati a la narración al aproximarse al desenlace. La historia, los personajes, las situaciones configuran formas de un tipo de melancolía más bien psicológica o sentimental, pero ésta termina

61 "Un nodo stringeva il cuore di Drogo; addio sogni del tempo lontano, addio cose belle della vita" (p. 224).

62 "Glio occhi di Drogo fissavano come non mai le giallastre pareti della Fortezza, le sagome geometriche di casematte e polveriere. Lacrime lente e amarissime calavano giù per la pelle raggrinzita, tutto finiva miseramente e non restava nulla da dire." (p. 247).

63 "l'orgasmo oscuro delle ore che passano" (p. 221).

64 "Poi ha cominciato a dimagrire, il volto si è fatto di un tristo colore giallo, i muscoli si sono afflosciati. Disturbi di fegato, diceva il dottor Rovina, oramai vecchissimo, determinato ostinatamente a finire lassù la vita" (pp. 230-231).

65 "I mali di testa e le penose diarree" (p. 231). 
evolucionando a esa forma más antigua -según estudió la medicina hipocrática- que afecta a unas funciones fisiológicas del cuerpo humano.

Por si los indicios aquí mencionados no fueran suficientes para diagnosticar la enfermedad que ha acabado por afectar no sólo al alma sino también al cuerpo de Giovanni Drogo, la narración aporta un último síntoma: el vértigo. La sensación de vértigo aparece, en varias ocasiones, cuando se va acercando el momento definitivo, y le obliga a permanecer en la cama:

Drogo bajó de la cama y le asaltó una oleada de vértigo, que, sin embargo, se disolvió lentamente. Ahora estaba ante el espejo y miraba espantado su rostro, amarillo y chupado ${ }^{66}$. (p. 185)

Bajo el signo de Saturno, Drogo ha perdido la vitalidad de su propio yo, confundido en un laberinto de tiempo y melancolía.

\section{ESE OTRO LABERINTO: EL DESIERTO}

Es ese «paisaje vacío y deshabitado» que se sitúa frente a la Fortaleza, en la llanura septentrional. Lo caracterizan su fuerte poder de atracción, su infinitud y su velo de misterio. Casi al principio de la novela resulta muy significativa una conversación en la que alguien pretende disuadir a Drogo para que olvide este monótono paisaje. $\mathrm{Su}$ insistencia resulta misteriosa porque parece querer ocultar algo, y ese algo que no se nombra lo convierte en un enigma:

- No vale la pena, teniente. Un paisaje monótono, no tiene nada de hermoso. Hágame caso, ¡no piense más en ello! (...)

- Me ha pedido usted lo único que no puedo concederle (...)

- ¿No hay ni siquiera una tronera, una ventana, por la que se pueda mirar?

- Sólo una. Sólo una, en el despacho del coronel (...) Pero no vale la pena, se lo repito, es un paisaje que no vale nada. Oh, ya se hartará de ese panorama, si se decide a quedarse. (...)

- Y no piense en ello: es un paisaje que no vale nada, se lo garantizo, un paisaje estupidísimo ${ }^{67}$. (p. 22)

Sin embargo, ante la insistencia de Drogo, esa misma noche el teniente Morel llevó a escondidas a Drogo al extremo de las murallas para que pudiese ver. Esta atracción es sentida por toda la tropa en general; las montañas eran bellas, pero nadie las miraba: «Drogo y los soldados, tendían instintivamente a mirar hacia el norte, a la desolada llanura, carente de sentido y misteriosa ${ }^{68}$ (p. 75).

66 "Drogo scese dal letto e fu colto da un'onda di vertigine, che però lentamente si dissolse. Adesso era davanti allo specchio e guardava spaventato il proprio volto, giallo e consunto." (p. 236).

67 “ «Non vale la pena, tenente. Un paesaggio monotono, non c'è proprio niente di bello. Dia retta a me, non ci pensi!» (...) «Lei mi ha chiesto» disse «proprio l'unica cosa che non posso concederle. (...)«Non c'è nemmeno una feritoia, una finestra, da cui si possa guardare?» «Una sola. Una sola nello studio del signor colonnello (...) Ma non ne vale la pena, le ripeto, un paesaggio che non val niente. Oh, ne avrà da stufarsi di quel panorama, se si decide a fermarsi. (...) Ma non ci pensi; un paesaggio che non val niente, le garantisco, un paesaggio stupidissimo.» (p. 47).

68 "Drogo e i soldati, tendevano istintivamente a guardare verso nord, alla desolata pianura, priva di senso e misteriosa." (p. 105). 
Pero la observación del desierto resulta inútil incluso con anteojo, «nunca hay nada $»^{69}$. Cuando Simeoni y Drogo lo escrutan con ese aparato, «las rocas, el desierto, las nieblas del fondo, todo parecía carente de sentido $»^{70}$. Es el desierto, que queda más allá de las murallas de la Fortaleza, ese espacio infinito, en el que todo permanece siempre oculto, desconocido, como misterioso enigma indescifrable. El enemigo nunca comparece y las fuerzas adversas se le ocultan. Los héroes trágicos de la antigüedad conocían a su enemigo, recuerda Argullol, pero para el hombre contemporáneo «el objeto de lucha deja de tener nombre propio». Más bien como les ocurre a los héroes románticos, Drogo, el último de ellos, después de que el romanticismo esté a punto de extinguirse, lucha contra sí mismo y no contra ningún adversario. Ha visto con nitidez el rostro de su enemigo y ahora puede perderle el miedo, sale de la oscuridad de su refugio-prisión para ver, en una noche de luna de primavera, «su última porción de estrellas» ${ }^{71}$.

Aunque allí fuera lo único que hay es la «nada», un espacio ilimitado ante el cual el hombre siente más la pequeñez y el sinsentido de su existencia, de su limitación, de su estupidez («un paisaje estupidísimo») de un absurdo existencial que hace desear que el desierto se convierta en un mar sosiego y paz. El deseo de infinitud y de paz sólo parece poderse realizar en un lugar fuera del tiempo, libre de la angustia de su necesidad. Drogo siente ese deseo y sueña en esos momentos «con un mundo remoto, un palacio, por ejemplo, a orillas del mar, en una suave noche de verano» ${ }^{72}$. La imagen no puede guardar una simetría contrastiva más clara con la del castillo en el desierto. Sería ése un lugar, en definitiva, en el que poder «paladear así un tiempo infinito, sin tener que angustiarse ${ }^{73}$.

¡Ay! Si pudiera verse a sí mismo, como estará un día, allá donde el camino acaba, parado a la orilla del mar de plomo, bajo un cielo gris y uniforme, y a su alrededor ni una casa, ni un hombre, ni un árbol, ni siquiera una brizna de hierba, y todo así desde tiempo inmemorial ${ }^{74}$. (p. 40)

El mar expresa ese deseo de paz e infinitud que quizá sólo puede el hombre encontrar cuando se ve a sí mismo ante la muerte y ha perdido el miedo. Este es el paisaje que Drogo encuentra ciento cincuenta páginas después, y lo reconoce $^{75}$.

69 “Non c'è mai niente" (p. 169).

70 “Le rocce, il deserto, le nebbie in fondo, tutto pareva vuoto di senso» (p. 200).

71 “L'ultima sua porzione di stelle" (p. 256).

72 “Un mondo desiderabile e lontano, un palazzo per esempio sulla riva di un mare, in una molle notte di estate...".

73 "Pregustare dinanzi a sé un tempo infinito, da non doversi angustiare" (p. 203).

74 "Guai se potesse vedere se stesso, come sarà un giorno, là dove la strada finisce, fermo sulla riva del mare di piombo, sotto un cielo grigio e uniforme, e intorno né un uomo né un albero, neanche un filo d'erba, tutto così da immemorabile tempo." (p. 69).

75 “La strada di Drogo era finita; eccolo ora sulla solitaria riva di un mare grigio e uniforme, e attorno né una casa né un albero né un uomo, tutto così da immemorabile tempo" (p. 252). 


\section{LA IDENTIDAD DEL HÉROE: “NESSUNO TI CHIAMARÀ EROE”}

Al final de la narración, cuando Drogo abandona la fortaleza, ya enfermo de soledad y tiempo, se encuentra frente a la salida de su laberinto: frente a la desnuda y trágica condición humana y a un destino común a todos los hombres. ¿Dónde o cómo sentirse un héroe?

Los «héroes» mueren a la luz de la luna, $\mathrm{y}$, sin embargo... La explanada de la Fortaleza se ve inundada de sol, mientras los soldados se aproximan a la esperada batalla y llega el deseado momento del enfrentamiento con el enemigo. Es el mismo momento en que llega el final para Drogo y, expulsado de la Fortaleza, excluido del combate militar, se dispone a otro tipo de batalla más personal. Es la hora de «último combate», «una batalla mucho más dura que la que esperaba antaño». Una escena sin público ni espectadores: igual que se vive en soledad, se muere en soledad. Y se conmueve el narrador «no hay nadie que mire, nadie que le llame valiente». La muerte podría ser hermosa «al aire libre», en acto de servicio, «con el cuerpo aún joven y sano ${ }^{76}$, pero esa sería la muerte de un héroe épico. Sin embargo, a Drogo no le ha sido dado ser un héroe en la vida, él como los otros ha tenido que conformarse con «la épica de los sueños» (Cercas: 2007).

Pero tampoco es un antihéroe, ni un héroe del absurdo; todavía es capaz de algo digno y noble, todavía es capaz de la virtud del héroe, la valentía. Al modo en que el capitán Ortiz reconoce que lo fue Angustina, para quien no hubo guerra ni confrontación con el enemigo: «Y, sin embargo, murió en una batalla. (...) Él supo morir en el momento justo», «como si le hubiera dado una bala. Un héroe, no hay más que decir» (p.119) ${ }^{77}$. Aprovechó la ocasión un día que para los otros fue más o menos como los demás.

Sus esperanzas de gloria se han visto larga y penosamente frustradas falta de acción heroica se tradujo en un largo ejercitarse en la espera del acontecimiento, en conocimiento de la desorientación y de la soledad fundamental del ser humano en la Fortaleza, en experiencia de todas las sensaciones de la melancolía. En definitiva, todo ello constituyó un largo aprendizaje en la paciencia y la desesperanza, un ejercitarse en la transformación física, emocional y espiritual de los efectos del lento fluir del tiempo, de forma que finalmente había aprendido a ser en el sentido profundo un hombre, y nada más. En ese punto preciso, la vida alcanza su sentido en tanto que preparación y adaptación para la asunción de la radical condición humana: cuando el héroe se despide de la gloria y encuentra su camino de conocimiento. Es en el momento en que se produce esta comprensión de la propia condición cuando el héroe es capaz de mostrar valentía, en el sentido de la antigua virtud de la andreia, según la concibe

76 "La definitiva battaglia"; "una ben più dura battaglia di quella che lui un tempo sperava"; "nella più nuda solitudine", "non c'è nessuno che guardi, nessuno che gli dirà bravo"; "all'aria libera", "col proprio corpo ancora giovane e sano" (p. 253).

77 "Eppure è morto come in una battaglia. (...) Lui ha saputo morire al momento giusto, effettivamente", “come se avesse preso una pallottola. Un eroe, c'è poco da dire" (p. 161). 
Aristóteles $^{78}$, como una praxis con relación a uno mismo, como un largo aprendizaje que resulta del entrenamiento de las propias emociones:

Valor, Drogo. Y trató de armarse de fuerzas, de resistir a fondo, de bromear con el tremendo pensamiento. Puso en ello todo su ánimo, en un arranque desesperado, como si partiera él solo al asalto contra un ejército. Y súbitamente los viejos temores se desvanecieron, las pesadillas se debilitaron, la muerte perdió su rostro helador, mudándose en cosa sencilla y conforme a natura. El comandante Giovanni Drogo, consumido por la enfermedad y los años, pobre hombre, hizo fuerza contra el inmenso portón negro y advirtió que las hojas cedían, dando paso a la luz ${ }^{79}$. (pp. 200-1)

"Nadie cantará tus alabanzas, nadie te llamará héroe o algo similar, pero precisamaente por eso vale la pena. (...) y sonríe incluso, si lo logras" ${ }^{80}$ dice el narrador, único testigo y relator del acontecimiento, en realidad, especie de corifeo en el momento en que se revela la verdadera identidad del héroe. Drogo, como la «odorata ginestra, / contenta dei deserti...» que cantó Leopardi (autor venerado por Buzzati entre sus primeras lecturas), la heroica «flor del desierto», «desdeñosa de la crueldad de Júpiter, arrogante ante el victorioso cerco de la rutina (...) encarna, en su austeridad y en su osadía, la reivindicación titánica de la identidad del Yo enfrentado al vacío.» (Argullol, 2008: 245). En Buzzati, como en Leopardi, se puede encontrar, junto con una visión pesimista y desoladora del mundo, el sentido de la dignidad humana. Sólo en el momento en que el hombre acepta, con sublime dignidad, lo inevitable, y es capaz de percibir en ese gesto la belleza, se produce ese momento de lucidez y liberación, que torna el espíritu a una libertad primitiva, que ya había dado por perdida («Qué alegría, se decía Drogo ante esa idea, como un niño, pues se sentía extrañamente libre y feliz» $\left.{ }^{81}\right)$.

Su muerte es la más triste y melancólica que podamos imaginar, porque se produce «en tierra extraña y desconocida, en el ambiguo lecho de una posada, viejo y afeado, sin dejar a nadie en el mundo ${ }^{82}$ (p. 200). Sin embargo, su valor o su virtud (la

78 Aristóteles en su Ética a Nicómaco (libro II, cap. 1, 1103f) concibe cualquier "virtud" o "areté" como el resultado de una práctica, un entrenamiento o un aprendizaje de las propias emociones, que el hombre no solo experimenta anímicamente, sino de forma somática; es con relación a éstas como debe mantenerse y buscarse "lo medio" o "lo intermedio". Así: «Uno se vuelve, por ejemplo, "valiente" (andrê̂os), esto, adquiere la areté de la "valentía" (andreía), mediante la práctica de la valentía. (...) Cualquier areté, toda areté, es un entrenamiento o habituación (héxis).» (V. Domínguez, "Aristóteles y la areté estoica en Vitae Philosophorum de Diógenes Laercio", en Asunción Herrera Guevara (2007: 3).

79 “Coraggio, Drogo. E lui provò a fare forza, a tenere duro, a cherzare con il pensiero tremendo. $\mathrm{Ci}$ mise tutto l'animo suo, in uno slancio disperato, come se partisse all'assalto da solo contro un'armata. E subitamente gli antichi terrori caddero, gli incubi si afflosciarono, la morte perse l'agghiacciante volto, mutandosi in cosa semplice e conforme a natura. Il maggiore Giovanni Drogo, consunto dalla malattia e dagli anni, povero uomo, fece forza contro l'immenso portale nero e si accorse che i battenti cadevano, aprendo il passo alla luce" (p. 254).

80 "Nessuno canterà le tue lodi, nessuno ti chiamerà eroe o alcunché di simile ma proprio per questo vale la pena" (pp. 253-54).

81 "Che gioia, si diceva Drogo al pensiero, come un bambino, poiché si sentiva stranamente libero e felice" (p. 255).

82 "In paese estraneo ed ignoto, sul generico letto di una locanda, vecchi e imbruttiti, senza lasciare nessuno al mondo" (p. 253). 
más heroica de ellas según Leopardi es la paciencia, precisamente porque carece de toda apariencia de heroísmo), le ha conducido al reconocimiento de sí mismo. Su presencia de ánimo, su fortaleza interior encuentra en la autoconciencia de su propia muerte, en la mirada hacia sí mismo, como en la contemplación del paisaje desértico, la fuerza del misterio, la belleza absoluta de la noche más melancólica: «Armándose de fuerza, Giovanni endereza un poco el busto, (...) echa aún un vistazo al exterior de la ventana, una brevísima mirada, para su última porción de estrellas. (...) y aunque nadie lo vea, sonríe ${ }^{83}$ (p. 202). Es la misma sonrisa melancólica de Ortiz, la de Angustina también en el momento de morir. Es la sonrisa del héroe, a pesar de todo, del que conserva, en actitud autoconsciente, en un último acto de conocimiento, su dignidad de hombre y, en su soledad, la «serenidad en el padecer» (Molinuevo, 1998: 147).

En medio de este desierto, Drogo siente «avanzar sobre él desde los extremos confines una sombra progresiva y concéntrica» ${ }^{84}$, pero -como en el "laberinto" de Borges- nada se espera, ni existe salida:

No habrá nunca una puerta. Estás adentro
y el alcázar abarca el universo.
Y no tiene ni anverso ni reverso
ni externo muro ni secreto centro

\section{BIBLIOGRAFÍA}

Alonso, Begoña (2002): Estudio de las configuraciones de una imagen poética: «Nuestras vidas son los ríos...», Salamanca, Ediciones Universidad de Salamanca, colección Vítor 92.

Argullol, Rafael (2008): El Héroe y lo Único, Barcelona, Acantilado.

Atchity, Kenneth John (1978): «Time in Two Novels of Dino Buzzati», Italica, 55, 1: pp. 3-19.

Bonifazi, Neuro (1982): Teoria del 'fantastico' (e il racconto 'fantastico' in Italia: TarchettiPirandello-Buzzati. Ravenna: Longo Editore.

Borelli, Luigi C. (1956): «Osservazioni su Dino Buzzati», Italica, 33: 2.

Borges, Jorge Luis (1989a): «Los dos reyes y los dos laberintos», El Aleph, en Obras completas, Barcelona, Emecé Editores, vol. I, 607.

Borges, Jorge Luis (1989b): «Laberinto», Elogio de la sombra (1969), en Obras completas, Barcelona, Emecé Editores, vol. II, 364.

83 “Facendosi forza, Giovanni raddrizza un po' il busto, (...) dà ancora uno sguardo fuori della finestra, una brevissima occhiata, per l'ultima sua porzione di stelle». Y después sonríe, en la oscuridad, "benché nessuno lo veda, sorride" (pp. 255-56).

84 "Dagli estremi confini" Giovanni Drogo "sentiva avanzare su di sé un'ombra progressiva e concentrica" (p. 252).

85 Borges, (1989b: 364). 
Borges, Jorge Luis (2005): Prólogo a Dino Buzzati, El desierto de los tártaros, Madrid, Gadir Editorial.

Cercas, Javier (2008): «La épica de los sueños», El País, 10 de enero.

Domínguez, Vicente (2007): “Aristóteles y la areté estoica en Vitae Philosophorum de Diógenes Laercio", en Asunción Herrera Guevara, De animales y hombres, Madrid, Biblioteca Nueva EdiUno, 37-44.

Gurméndez, Carlos (1990): La melancolía, Madrid, Espasa-Calpe.

Lambote, Marie-Claude (1999): Esthétique de la mélancolie, Aubier.

Mazzali, Ettore (1973): Introducción a Il deserto dei Tartari, Milano, Mondadori.

Metallo, Mariapia (1982), Critica letteraria 10: pp. 615-617, reseña de: Mario B. Mignone (1981), «Anormalità e angoscia nella narrativa di Dino Buzzati». Ravenna, Book Review.

Molinuevo, José Luis (1998): La experiencia estética, Madrid, Editorial Síntesis.

Pietrosi, Luciana (1965): «Dino Buzzati», Italica, 42: 4, 391-402.

Sala, Alberico (1970): Prólogo a Dino Buzzati, Il deserto dei Tartari (1940), M i l a n o , Mondadori.

Suñén, Juan Carlos (1991): Prólogo a Dino Buzzati, El desierto de los tártaros (versión castellana de Esther Benítez), Madrid, Debate. 